W. Köhler S. Wiegand (Eds.)

\title{
Thermal Nonequilibrium Phenomena in Fluid Mixtures
}




\section{Contents}

Part I Concepts, Theory, and Computer Simulations

Computer Simulations of Thermal Diffusion in Binary Liquid Mixtures

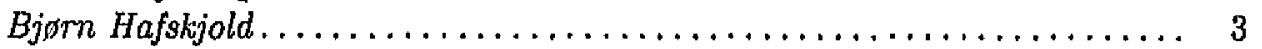

Thermodiffusion in the Critical Region

Jutta Luettmer-Strathmann ........................... 24

On the Theory of the Soret Effect in Colloids

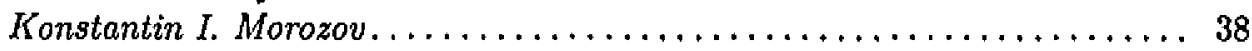

Principle of Entropy Maximization

for Nonequilibrium Steady States

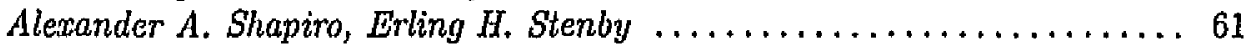

A Comprehensive Theory of the Soret Effect

in a Multicomponent Mixture

Leo J.T.M. Kempers ............................ 74

Thermodiffusion and Nonlinear Heat Equation

Ryszard Wojnar .................................. 93

Nonequilibrium Concentration Fluctuations

in Binary Liquid Systems Induced by the Soret Effect

Jan V. Sengers, José M. Ortiz de Zánate.................... 121

Thermodiffusion in Ionic Solids - Model Experiments and Theory

Jürgen Janek, Carsten Korte, Alan B. Lidiard................. 146

Hip, Hip, Soret!

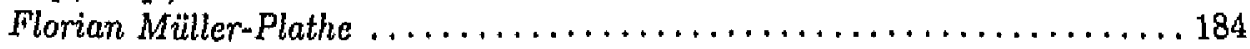

Part II Experimental Techniques and Special Systems

Measurement of Transport Coefficients

by an Optical Grating Technique

Simone Wiegand, Werner Köhler ............................ 189 
A Survey of the Thomaes Flow Cell Method for the Soret Coefficient

Guy Chavepeyer, Jean-François Dutrieux, Stéfan Van Vaerenbergh,

Jean-Claude Legros.................................... 211

Validity Limits of the FJO Thermogravitational Column Theory Javier Valencia, Mohamed Mounir Bou-Ali, Oscar Ecenarro, José Antonio Madariaga, Carlos María Santamaría ........................ 233

Determination of Thermodiffusion Parameters from Thermal Field-Flow Fractionation Retention Data Michel Martin, Charles Van Batten, Mauricio Hoyos .................250

Thermodiffusion of Polymer Solutions in Convectionless Cells Martin E. Schimpf ........................................ 285

Part III Convection and Porous Media

Soret Effect and Free Convection:

A Way to Measure Soret Coefficients

Jean-Kurl Platten, Jean-François Dutrieux, Guy Chavepeyer.............313

Convective Patterns in Binary Fluid Mixtures with Positive Separation Ratios

Björn Huke, Manfrel Lücke ............................... 334

Convective Instability of Magnetized Ferrofluids:

Influence of Magnetophoresis and Soret Effect

Mark I. Shliomis . ...................................... 355

On the Soret-Driven Thermosolutal Convection

in a Vibrational Field of Arbitrary Frequency

Boris L. Smorodin, Bela I. Myznikova, Igor O. Keller . . . . . . . . . . . . . . 372

Thermodiffusion in Porous Media and Its Consequences

Pierre Costesèque, Daniel Fargue; Philippe Jamet ................... 389

Soret Effect and Mixed Convection in Porous Media

Mohamed Najib Ouarzazi, Annabelle Joulin, Pierre-Antoine Bois, Jean K.

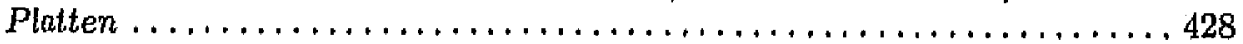

Soret Effect in Multicomponent Flow Through Porous Media:

Local Study and Upscaling Process

Bruno Lacabanne, Serge Blancher, Renó Creff, François Montel........... 448

Index 